\title{
NECESSIDADES FORMATIVAS PARA A AÇÃO DOCENTE INCLUSI- VA DE PROFESSORES DE EDUCAÇÃO FÍSICA ESCOLAR
}

\author{
Milena Pedro Morais \\ Universidade São Judas Tadeu, São Paulo, São Paulo, Brasil. \\ Graciele Massoli Rodrigues \\ Universidade São Judas Tadeu, São Paulo, São Paulo, Brasil. \\ Isabel Porto Filgueiras \\ Universidade São Judas Tadeu, São Paulo, São Paulo, Brasil.
}

\section{Resumo}

O objetivo da pesquisa foi analisar de que forma os Jogos Escolares Inclusivos contribuíram para a ação docente inclusiva dos professores de Educação Física Escolar do município de Itanhaém e identificar as barreiras enfrentadas pelos professores para participação nesse evento. Participaram 20 professores de Educação Física. A coleta de informações ocorreu com o uso de entrevista semidirigida e a análise foi por meio da análise de conteúdo proposta por Bardin (2011), o que configurou quatro categorias para discussão. Concluímos que um conjunto de fatores interfere de forma negativa na ação docente inclusiva, porém, ao atuar como agentes transformadores, os professores têm conseguido atingir a comunidade escolar e a família dos alunos, mostrando o potencial da criança e o quanto ela é capaz de evoluir no processo ensino/aprendizado.

Palavras-chave: Educação Física Escolar Inclusiva. Formação de professores. Inclusão Escolar.

\section{TRAINING NEEDS FOR THE INCLUSIVE TEACHING ACTION OF SCHOOL PHYSICAL EDUCATION TEACHERS}

\begin{abstract}
The objective of the research was to analyze how the Inclusive School Games contributed to the inclusive educational action of the teachers of Physical School Education of the municipality of Itanhaém and to identify the barriers faced by the teachers to participate in this event. Twenty teachers of Physical Education participated. The information collection took place through the use of a semi-directed interview and the analysis was through the content analysis proposed by Bardin (2011) that configured four categories for discussion. We conclude that a set of factors interferes in a negative way in the inclusive teaching action, but, acting as transforming agents teachers have been able to reach the school community and the students' family, showing the potential of the child and how much it is able to evolve in the teaching / learning process.
\end{abstract}

Keywords: Inclusive School Physical Education. Teacher training. school inclusion. 


\section{NECESIDADES FORMATIVAS PARA LA ACCIÓN DOCENTE INCLUSIVA DE PROFESORES DE EDUCACIÓN FÍSICA ESCOLAR}

\section{Resumen}

El objetivo de la investigación fue analizar de qué forma los Juegos Escolares Inclusivos contribuyeron a la acción docente inclusiva de los profesores de Educación Física Escolar del municipio de Itanhaém e identificar las barreras enfrentadas por los profesores para participar en ese evento. Participaron 20 profesores de Educación Física. La recolección de informaciones ocurrió con el uso de entrevista semi-dirigida y el análisis fue por medio del análisis de contenido propuesto por Bardin (2011) que configuró cuatro categorías para discusión. Concluimos que un conjunto de factores interfiere de forma negativa en la acción docente inclusiva, sin embargo, al actuar como agentes transformadores los profesores han logrado alcanzar la comunidad escolar y la familia de los alumnos, mostrando el potencial del niño y cuanto es capaz de evolucionar en el mismo proceso de enseñanza / aprendizaje.

Palabras clave: Educación Física Escolar Inclusiva. Formación de professores. Inclusión Escolar.

\section{Introdução}

A Educação Física Inclusiva tem encontrado muitas barreiras desde sua concepção de fato, em meados de 1990. Entretanto, várias iniciativas buscam alterar a realidade posta, dentre elas o desenvolvimento de jogos e eventos que estimulam a participação de pessoas com diferentes deficiências e comprometimentos.

Para que essas iniciativas possam se tornar realidade, muitos esforços de gestores e professores precisam caminhar juntos, a fim de que se efetive a realização de propostas inclusivas. Congregar num evento turmas heterogêneas de alunos, potencializar capacidades e habilidades diferentes, respeitando as particularidades e especificidades, têm sido o objetivo comum nesse tipo de iniciativa, que busca desdobramentos para a continuidade do processo, além do período de realização dos jogos propriamente ditos.

Um dos fatores que impacta a concretização de ações docentes inclusivas é a formação profissional incipiente. El Tassa e Cruz (2016) afirmam que a preparação profissional para a docência ocupa posição de destaque em debates acadêmicos, profissionais e políticos no que se refere à inclusão escolar de pessoas com deficiência. A necessidade de uma preparação adequada dos profissionais da educação para atender demandas específicas de alunos tem sido consenso acerca da inclusão escolar de pessoas com deficiência.

O movimento de implementação da inclusão, ao mesmo tempo em que se desenvolve de forma impositiva, pulveriza a naturalidade da ação inclusiva em qualquer ambiente. Isto se deve ao fato de a inclusão escolar ter sido apresentada como alternativa possível de ser desenvolvida e hoje representa a única possibilidade cabível para que os alunos com deficiência estabeleçam relações de aprendizagem e se enquadrem no ideal de aluno proposto pela escola (EBBING; BRITTES, 2016). Porém, essa colocação nos traz a seguinte reflexão: qual é o ideal de aluno proposto pela escola? O modelo de ensino educacional vigente mostra sinais de esgotamento e a diversidade humana vem sendo cada vez mais destacada como a condição principal para entendermos como aprendemos e como percebemos o mundo e a nós mesmos. Na contrapartida desta discussão, observamos que os sistemas escolares estão organizados de forma a separar os alunos como normais e com deficiência, nas modalidades de ensino regular e especial, uma visão reducionista que categoriza, classifica e ignora a naturalidade do ser humano no âmbito afetivo, social e cognitivo, como se a deficiência fosse parte do indivíduo, fixada nele e impedindo-o de evoluir além dessa condição (MANTOAN, 2004). 
Nesse sentido, conforme Rodrigues (2013, p. 61), faz-se necessária uma reforma inclusiva que compreende a escola tal como a conhecemos; uma "reforma no sentido de modificar as formas transmissivas, uniformes e indiferenciadas como os alunos são tratados na escola tradicional", no sentido da desvalorização da individualidade do aluno. Entende-se o termo escola "tradicional" como o modelo escolar que ainda não foi reconfigurado por uma nova realidade em seu processo de ensino e experiências vivenciadas, como a escola que não sofreu mudanças ao longo do tempo.

A educação inclusiva tem sido entendida como um movimento político nas escolas, uma prática de inclusão social que vai além do simples discurso porque visa à condução do ser humano ao caminho do bem e à inclusão no mundo social, de forma que os que antes eram afastados e excluídos estão agora presentes nos mais diversos espaços (EBBING; BRITTES, 2016).

Com relação à educação física inclusiva, Lima (2011) afirma que a Lei de Diretrizes e Bases da Educação Nacional (LDBEN) 9394/96 aponta importantes modificações nas políticas de atendimento educacional e apoio à equipe gestora da escola, professores e funcionários, a fim de que o processo de ensino ocorra de forma equitativa e com qualidade. Isto porque se observa a falta de conhecimento da comunidade educativa e órgãos governamentais, tendo em vista que a exclusão e a segregação vêm acontecendo há muito tempo, podendo ser consideradas práticas tão antigas quanto a humanidade.

Para Falkenbach et al (2011), a Educação Física é um ponto-chave de possibilidade ou de obstáculo para que o processo de ensino se torne ou não inclusivo, pois entre os fatores que a favorecem estão a flexibilidade e autonomia do professor no que se refere à base de conteúdos, que facilitam a diferenciação curricular e as inúmeras possibilidades de movimento, além da preparação adequada de todos os profissionais da educação. E a preparação dos professores de educação física é um dos fatores primordiais para promover mudanças e concretizar ações inclusivas.

Cabe ressaltar que a formação em serviço é um componente fundamental de preparação de professores, a qual se relaciona ao ambiente educacional em que ele está inserido. A formação em serviço pode auxiliar as redes de ensino e professores a compreenderem que o desconhecimento das especificidades das pessoas com deficiência não é uma barreira às ações inclusivas, pois se entende que "a mediação do educador pode contribuir ou não para facilitar os processos de aprendizagem e desenvolvimento da criança com deficiência consigo mesma, na interação com seus pares e objetos" (CHICON; SILVA, 2011, p. 3), desde que o professor esteja consciente da intencionalidade de sua ação.

Assim, se o professor de Educação Física se mantiver em uma posição de passividade em relação à criança com deficiência, ele pouco potencializará oportunidades para que essa criança aprenda; por outro lado, se esses professores se mantiverem de forma ativa, possibilitarão à criança um meio de desenvolvimento motor, cognitivo, social e afetivo que de outras formas não aconteceria (CHICON e SILVA, 2011).

Aportada nas questões supracitadas, no ano de 2014 foi realizado no município de Itanhaém-SP a primeira edição dos Jogos Escolares Municipais, que teve o tênis de mesa, atletismo e bocha adaptada como modalidades inclusivas. $\mathrm{O}$ evento surgiu da inquietude dos professores de Educação Física Escolar do município que, incomodados com a falta de participação dos alunos com deficiência durante as aulas, buscavam ações para fazer valer a inclusão. Esta preocupação foi levantada durante os encontros de formação continuada propiciados pela Secretaria de Educação. Com a intenção de atender às requisições dos professores, foi criado o Projeto de Iniciação Paradesportiva, que objetivou capacitar todos os professores de Educação Física Escolar para ampliar o acervo de estratégias inclusivas para que os alunos com deficiência pudessem ter acesso às atividades motoras e modalidades adaptadas, visando a uma vivência inclusiva esportiva e a participação nos Jogos Escolares Municipais. As modalidades 
foram escolhidas pelos próprios professores em razão do potencial de adaptabilidade dos materiais que tinham acessibilidade. $\mathrm{O}$ tênis de mesa, o atletismo e a bocha adaptada foram apresentados e diferentes estratégias foram desenvolvidas em quatro encontros semanais, que ocorreram entre os meses de agosto e outubro de 2014.

O Projeto de Iniciação Paradesportiva catalisou a ação de formação docente que mobilizou os professores para que tivessem contato com as modalidades e pudessem vivenciar, refletir e elaborar estratégias que facilitassem a aprendizagem das atividades e favorecessem a interação de todos os alunos durante as aulas.

Com vistas ao objetivo de terem a participação inclusiva dos alunos com e sem deficiência nas modalidades, os professores visaram a garantir o acesso à vivência esportiva nos Jogos Escolares de 2014 com equidade. O evento contou com vinte e três escolas participantes, sendo dezesseis da rede municipal, três unidades estaduais e quatro da rede privada de ensino. Das mencionadas, sete delas se inscreveram nas modalidades inclusivas. Essa ação formativa foi a base das discussões que seguirão.

\section{Método}

A pesquisa se caracterizou como um estudo de caso de natureza qualitativa (THOMAS; NELSON, 2002). A pesquisa contou com 20 professores de Educação Física do município de Itanhaém-SP, que participaram da ação docente formativa inclusiva e que estiveram nos Jogos Escolares Inclusivos no segundo semestre de 2014. Esses participantes representam 21 escolas da cidade, sendo 13 escolas municipais, 2 escolas privadas e uma escola estadual. A amostra foi não probabilística. Foram excluídos os professores de Educação Física que se inscreveram nas modalidades esportivas inclusivas, mas não compareceram com seus alunos na data do evento.

A pesquisa utilizou como instrumento uma entrevista semiestruturada, composta por 4 temas com questões acerca do problema de pesquisa e dos objetivos da investigação. As entrevistas foram agendadas previamente, gravadas e transcritas na íntegra. Os dados foram tratados com base na análise do conteúdo preconizada por Bardin (2011). Todos os procedimentos éticos foram seguidos e esta pesquisa foi aprovada pelo Comitê de Ética em Pesquisa da Universidade São Judas Tadeu sob o parecer no 919.493.

\section{Discussão e resultados}

As ideias centrais suscitadas das entrevistas deram origem a quatro categorias temáticas: Por um compromisso com a acessibilidade; Desvendar as potencialidades é preciso; Nos passos do paradesporto inclusivo e A unidade na especificidade: a inclusão como estratégia. As falas estão identificadas com siglas para que seja mantido o anonimato. Os professores participantes foram codificados pela letra $(\mathrm{P})$ e por um número subsequente de 01 a 20 seguindo-se a ordem das entrevistas realizadas.

\section{Por um compromisso com a acessibilidade}

Para os professores, alguns fatores dificultam a ação educativa inclusiva durante as aulas, como o número elevado de alunos em sala de aula, a falta de materiais em quantidade suficiente para todos os alunos e a precária infraestrutura, como a falta de acessibilidade nos prédios escolares, conforme afirma P16:

[...] se você não tem nem uma privada pequena pra criança que é pro ensino infantil, regular ali, quanto mais pra uma criança de educação inclusiva [...] tem que estrutu- 
rar a estrutura não só física como organizacional, de metodologias, de como pensar a educação [...] ( P16)

Silva (2013) sinaliza que a acessibilidade na estrutura física é fundamental para o sucesso do processo de inclusão escolar, porém, isoladamente, não garante a efetividade do trabalho inclusivo. É necessária uma mudança de postura e atitude da equipe gestora e da comunidade escolar, garantindo a acessibilidade humana e aceitação do outro, independentemente de sua condição. Saldanha et al (2015) afirmam que o processo de inclusão escolar deve prever o comprometimento coletivo da escola, assim como a preparação de um projeto políticopedagógico e o planejamento de formação continuada para todos os envolvidos na comunidade escolar. Nesse sentido, importa também analisar os recursos simbólicos da equipe escolar para transformar o contexto e criar soluções para a gestão dos recursos materiais (CANÁRIO, 1992). Para o autor, todo processo de inovação pedagógica depende da "descoberta da escola", o que inclui sua lógica institucional, seus recursos sociais, simbólicos e materiais e como são significados quando a equipe escolar trabalha o seu projeto educativo.

Esta mudança de postura e atitudes representa uma reorganização metodológica com relação à educação, como citado por um dos professores. É preciso encarar as limitações de um sistema de ensino baseado historicamente na homogeneização e perceber o que é necessário modificar para que a escola possa, de fato, atender a todos, com olhar direcionado à individualidade e identidade de cada aluno. Muitas vezes, o aluno com deficiência ainda não é visto como os demais; apesar de a igualdade ser garantida em termos legais, esse público não tem acesso às condições plenas que necessitam para que o ensino de fato seja inclusivo.

A legislação educacional circunscreve a igualdade de direitos para a pessoa com deficiência para que ela seja vista como qualquer outro cidadão e seja valorizada e respeitada em suas diferenças cultural, biológica, histórica e social (NEVES, 2013). Não se trata de garantir a simples integração do aluno com deficiência ao ambiente escolar, mas de garantir sua efetiva participação, aprendizagem e desenvolvimento.

Desta forma, as políticas públicas de educação garantem a matrícula e o acesso do aluno com deficiência à escola, mas não tem garantido a permanência com qualidade, como mostraram Lima et al (2008), pois a lei foi modificada visando à inclusão, porém a sociedade se mantém excludente, inclusive no interior da escola.

Ainda em relação à infraestrutura e materiais, os professores citam que a adaptação de materiais para atender às necessidades de aprendizagem do aluno com deficiência demanda energia e atenção, dificultando ou impossibilitando a atuação do professor, mesmo que ele tenha conhecimentos sobre como atuar com esse estudante, conforme expressa P03:

[...] além da parte teórica né, parte de conhecimento e também a parte de material, local adequado, então tudo isso acaba prejudicando... a gente tem que se virar muito, tem que ter uma criatividade muito boa pra conseguir colocar em prática o pouco que a gente aprendeu [...] (P03).

Percebe-se que as dificuldades encontradas pelos professores para propiciar a participação de todos os alunos durante as aulas são passíveis de enfrentamento mediante o acesso à informação adequada sobre estratégias inclusivas. Nesse sentido, Gitahy et al (2016) afirmam que a falta de formação específica traz prejuízos com relação ao uso adequado dos recursos e seleção das melhores estratégias de ensino, que devem ir ao encontro das necessidades educativas dos alunos. Os autores ressaltam a importância da parceria entre o professor regente e o professor das salas de recursos multifuncionais, os quais podem auxiliar na elaboração do planejamento de aula e na seleção de materiais. 
Essa parceria poderá suprir parte da angústia sentida pelos professores com relação à necessidade de informação, pois o professor da sala de recursos multifuncionais é o especialista na área que os professores alegam não ter formação adequada. Isso implica o desenvolvimento de processos formativos colaborativos no interior da escola, como defendem Nóvoa (1992) e Imbernón (2000).

\section{Desvendar as potencialidades é preciso}

Os professores levantaram questões relacionadas às dificuldades que encontram para lidar com a limitação consequente da deficiência e explicitam como buscam contornar essa dificuldade. Por falhas na formação inicial e continuada, muitos professores percebem barreiras para incluir alunos com deficiência, em razão da falta de informação sobre as características de cada deficiência, sobre a possibilidade de estratégias de ensino a serem desenvolvidas e objetivos almejados. Afirmam que desconhecem o potencial de cada aluno e se assustam quando as crianças evoluem, como se a limitação e o aprendizado fossem dependentes entre si, como se o fato de o aluno com deficiência possuir limitações consequentes da condição de deficiência o impedisse de avançar no processo de ensino, como aborda P03:

[...] uma coisa é trabalhar com o deficiente auditivo, visual, outra coisa é trabalhar com o cadeirante, paralisia cerebral, é completamente diferente... muitos, não só cadeirantes, muitos tem outras [...], cadeirantes com pc... então é.. que dificulta ainda mais o trabalho né, então aos poucos a gente está tentando chegar em uma aula agradável para todos[...](P03).

Além das questões anteriormente citadas, que interferem na atuação do professor com a criança com deficiência, nota-se que os professores encontram dificuldades em lidar com o corpo "imperfeito", que talvez não seja capaz de realizar de forma técnica o movimento almejado. A relação que os professores de educação física estabelecem com a questão do "corpo" fica muito clara quando recebem um aluno que foge aos padrões aos quais estão habituados. Segundo Ribeiro (2009), a condução de práticas esportivas adaptadas tem sido pouco explorada pelos professores e as razões desse fato estão na rigidez e na falta de alteração do currículo de educação física, que está baseado na racionalidade técnica e na esportivização da aula, visando ao rendimento e à competitividade. Outro aspecto relacionado às dificuldades apontadas pelos professores deve-se à medicalização da deficiência e à necessidade do professor ter nas mãos um diagnóstico do aluno para que se inicie o processo de ensino com estratégias adaptadas e adequadas ao desenvolvimento objetivado, como aponta P06:

[...] as dificuldades maiores são que as pessoas não tem noção do que vem a ser essas deficiências, de quais são realmente os... não é movimentos, vamos dizer assim... ah... as atitudes que você tem que ter diante dessa criança, até que ponto você pode chegar com essa criança.. eles querem superproteger da situação normalmente passada pelos pais e até os pais não têm essa relação de saber o que pode e o que não pode, o limite dessa criança e acaba acontecendo isso, então a superproteção me atrapalha muito, os pais, por exemplo, dar remédio demais para essas crianças, ou não dar o remédio para essas crianças, quer dizer eles não cuidarem dessa criança da forma correta, ou até do que a gente falou que é o de não aceitar a deficiência, então muita criança tá se perdendo aí pelo tempo porque eles simplesmente acham que aquela criança vai melhorar uma hora, e que imagina[...](P06).

Com relação à medicalização do processo inclusivo, Armstrong (2014) afirma que a autoridade médica ainda detém grande poder sobre decisões acerca de questões educativas da 
criança com deficiência, essa é uma característica histórica que permeia ainda o cotidiano das instituições escolares, de forma que os avanços obtidos pela medicina tornaram as crianças menos dependentes de cuidados e orientação e mais próximas da escola. A autora afirma ainda que, por outro lado, o legado contínuo de procedimentos referentes ao diagnóstico, categorização e medicalização da deficiência têm provocado o afastamento do aluno com deficiência do processo educativo.

O modo como o professor de educação física conduz o processo de ensino/aprendizagem, considerando o aluno como um ser global (motor, afetivo, social e cognitivo) e valorizando as diferenças biopsicossociais existentes no meio escolar, faz com que o grupo discente vivencie, a cada dia, novas situações sob a ótica inclusiva e essas ações criam uma cultura de valorização e respeito ao aluno com deficiência por parte da comunidade escolar.

Nesse processo, os alunos com deficiência passam a ser vistos em igualdade de direitos e condições pelos próprios alunos do grupo escolar e, nessa cultura que prima pela valorização da diversidade e respeito, o aluno com deficiência amplia aprendizagens e conquistas, tornando-se uma referência que pode incentivar a iniciação de outros alunos na prática esportiva.

Ainda sob essa perspectiva, o papel do professor de educação física assume a função de agente transformador. Isso pode ser ampliado para além dos atores escolares diretos para atingir uma parceria com a escola e a família, como afirmam Rodrigues e Freitas (2011). A participação dos pais no processo de inclusão escolar é de suma importância no encorajamento e para a superação de barreiras que são impostas pelo meio. Esta vivência fica explícita na fala de P06:

[...] através do esporte a gente tem essa possibilidade, porque quando eles chegam na escola com uma medalha, assim, felizes pelo que eles fizeram, as pessoas notam e começam a perguntar, mas como? Mas como? E é uma forma de você explicar que realmente eles tem capacidade e eles começam a visualizar que é de verdade a situação, né? [...] (P06).

Foi marcante para os professores criar oportunidades para a participação do aluno com deficiência nos jogos escolares como uma forma de creditar às crianças o potencial que os pais nem sempre visualizam.

\section{Nos passos do paradesporto inclusivo}

Os professores abordaram questões do processo inclusivo que permeiam a prática esportiva e a participação efetiva do aluno com deficiência nas aulas de Educação Física escolar como: a ocorrência da aceitação advinda dos colegas de turma a partir do momento em que o aluno com deficiência obtém a conquista de uma medalha nos jogos escolares inclusivos. Tal conquista parece "certificar" o aluno com deficiência para aceitação no grupo, o que, segundo os professores, é um fator facilitador no processo inclusivo. O paradesporto na aula de educação física foi um meio de sensibilização dos alunos que não apresentam qualquer tipo de deficiência e transcende a prática esportiva. A vivência Paradesportiva pode colaborar com a aula de educação física escolar, como afirma P06:

[...] a partir deste momento, as crianças já se ajudam mesmo, não tem essa discriminação, não tem nada disso, mas, alguns limites fazem com que elas se afastem em determinados momentos, a partir do momento que essa criança vai para os jogos escolares, volta com todo mundo contente e ah porque ele conseguiu, quer dizer, eles se motivam a estar mais próximos dessa criança, eles se motivam a motivar essa cri- 
ança e eles se motivam a participar o tempo inteiro com essa criança, então eu acho que aí se forma totalmente a inclusão, então eu acho que os jogos é a oportunidade, tanto para os que não são portadores, de aprender a lidar com os portadores, tanto quanto os portadores a ficarem motivados a estar junto dos que não são portadores [...] (P06)

A conquista representada através do símbolo da medalha diferencia o aluno com deficiência e o leva a ser admirado pelos colegas. A participação do aluno com deficiência nos jogos escolares inclusivos oportunizou a convivência e elevou os alunos com deficiência à igualdade no direito de participação. Deve-se valorizar as diferenças para além da igualdade no acesso, mas com a diferenciação dos aspectos biopsicossociais que são condições naturais humanas (RODRIGUES, 2014).

Assim, segundo Armstrong e Moore (2014), a educação inclusiva não deve estar focada em identificar um grupo "excluído" e solucionar a questão, mas em transformar culturas e práticas, pois estas envolvem e afetam todos os membros da comunidade. O professor é o grande agente desta ação transformadora.

\section{A unidade na especificidade: a inclusão como estratégia}

Alguns professores abordaram fatores que facilitariam o trabalho com o aluno se fosse realizado em ambiente separado dos demais (segregado), alegando que só é possível trabalhar com o aluno com deficiência em horário e grupo separado dos outros alunos, acreditando que possam dar mais atenção ao aluno com deficiência, explicitando as dificuldades que enfrentam ao trabalhar em uma perspectiva inclusiva. Os professores defendem esse modelo como melhor alternativa para que haja inclusão no esporte, pois uma sala com grande número de alunos com e sem deficiência dificulta o processo de inclusão escolar, como aponta P14:

[...] quando nós temos uma sala com 30 crianças e você tem uma aula planejada para 30 crianças, você sempre tem que ter uma aula especial, entre aspas, você tem que ter um cuidado a mais com essa criança, pra essa pessoa, pra essa outra criança, e aí acaba assim dificultando a aula entendeu? Eu acho que esse é o grande problema porque, se fosse tudo com crianças, entre aspas, normais, não vamos dizer deficientes, mas as nossas crianças são muito bagunceiras, muito sem educação e aí você pega um pouquinho da sua aula dá uma atenção pra um lado, as outras vinte pega fogo, entendeu? [...] (P14).

Ficou explícito que não há consenso entre os professores porque, apesar de acreditarem no processo de inclusão escolar, não conseguem visualizar formas de transpor as barreiras que encontram. Tais barreiras são vistas como resultado da formação incipiente frente ao desenvolvimento de estratégias que propiciem a este professor base teórica e uma gama de vivências para solucionar questões cotidianas acerca da inclusão de alunos com deficiência no ambiente escolar.

Com relação à formação profissional, observa-se no discurso dos professores a negativa em relação ao preparo para atuar com a criança com deficiência e as dificuldades encontradas na busca destas informações. Segundo Guizzo (2014), a formação é o grande nó do processo de inclusão escolar, pois, apesar dos professores de educação física sentirem-se despreparados para atuar com a criança com deficiência, demonstram interesse em colaborar com o processo de ensino no sentido de uma ação educativa inclusiva. Percebe-se, por outro lado, que o processo de ensino é um movimento constante e que este sentimento de despreparo dos professores acarreta consequências danosas à qualidade de ensino, indicando que a formação 
docente não deve ser desconsiderada quando se pensa em inserir e inovar nas práticas escolares inclusivas.

A utilização de estratégias criadas por ensaio e erro e a importância que os professores atribuem ao processo de desenvolvimento da criança em um ambiente de convivência inclusiva dentro da escola emergiram no grupo pesquisado. São mencionadas muitas dificuldades, que comprometem a criação de estratégias de ensino para que o aluno com deficiência participe da aula integrado ao grupo. Percebe-se que, por conta de lacunas na formação e/ou informação, os professores se culpam pela falta de atenção necessária ao aluno com deficiência e denunciam que a indisciplina do grupo de alunos durante as aulas agrava quando a atenção é dirigida ao aluno com deficiência; alegam que a indisciplina impossibilita a ação educativa inclusiva, como cita P02:

[...] o ideal a gente, que numa sala que tem 30 alunos ou mais, a gente sabe que tem muitos... a gente acaba não podendo dar a atenção que eles necessitam que seria ideal para eles pra ter esse desenvolvimento e isso não é uma questão de eles não conseguirem, pelo contrário, se tivesse esse tempo o desenvolvimento deles, num geral, escolar, seria bem maior [...] (P02).

Por outro lado, por meio das estratégias de ensino utilizadas para promoção da ação educativa inclusiva durante as aulas, o professor busca potencializar as crianças e poderá direcionar a participação de todos. Para esse contexto, a escola precisa agir no sentido de fortalecer as ações inclusivas, o respeito e a valorização da diversidade durante as aulas de educação física, nas quais os alunos com deficiência são vistos como os demais, com potenciais e dificuldades, garantindo a eles a igualdade de direitos e o reconhecimento à individualidade, como aponta P04:

[...] porque os alunos da minha escola, eles já eram de incentivar os alunos de inclusão a fazer as coisas, toda vez que eu ia fazer uma atividade os alunos de inclusão eles eram inclusos mesmo, os próprios alunos, não era eu que obrigava os alunos a incluir os alunos de inclusão, como é uma coisa que já vem ao longo dos anos... ah.. fulano vai ser da minha turma, na hora de dividir, as vezes o aluno de inclusão é até mais disputado do que outro aluno e o fato dele ter ido bem, dele ter se saído bem nos jogos, fez com que todo mundo ficasse orgulhoso dele [...] (P04).

Segundo Chicon e Sá (2013), as práticas educativas na Educação Física precisam reconhecer em seus processos pedagógicos a individualidade dos alunos e considerar as diferentes situações em que ela se manifesta, seja por questões de ordem biológica ou sociocultural, favorecendo a flexibilização do currículo e a adequação dos processos de avaliação, ao possibilitar que o processo de inclusão escolar tenha a diversidade humana como premissa.

\section{Considerações finais}

Concluímos que há um conjunto de fatores que circunda a ação profissional, que vai desde a formação inicial até as questões estruturais, interferindo de forma negativa para o sucesso da ação docente inclusiva. Por outro lado, visualizamos que, ao atuarem como agentes transformadores, os professores têm conseguido atingir a comunidade escolar e a família do aluno.

Mesmo com os relatos de dificuldades no desenvolvimento de atividades em aula de forma inclusiva, os professores de educação física escolar de Itanhaém que fizeram parte desse estudo vêm tentando ressaltar o potencial de seus alunos e o quanto eles são capazes de 
evoluir no processo ensino/aprendizagem. Para os pesquisados, o evento dos Jogos Escolares Inclusivos fomentou possibilidades de ações docentes inclusivas no âmbito da Educação Física Escolar que poderão ser ampliadas com a continuidade dessa ação e com o interesse individual por parte dos professores, o que poderá implicar em um ambiente escolar mais acolhedor nas práticas das atividades físicas e nos jogos, se tiverem abertura para mudança na estrutura e organização.

Ações formativas de professores dirigidas à inclusão de alunos com deficiência nas aulas de educação física devem ser empreendidas, mas não mais como ações pontuais e transmissivas que abordam a questão da inclusão sem dialogar com os contextos da prática dos professores ou que consideram a prática como mera aplicação da teoria (IMBERNÓN, 2000). As ações formativas precisam conversar com as questões éticas, morais e políticas da educação inclusiva, investindo na aprendizagem colaborativa, na troca de experiências e na profissionalização docente. Para trabalhar de forma inclusiva, os professores de Educação Física devem ser estimulados a explicitar e refletir sobre suas práticas, gerando, de forma coletiva, um saber-fazer criativo que os permita agir em contextos complexos por meio de trocas com seus alunos (ALARCÃO, 1996, p. 14). Assim, gestores da formação docente de professores de Educação Física precisam ouvir os professores, considerar seus pontos de vista e reflexões durante os processos formativos, buscando propiciar um suporte para criação de alternativas que se sustentem nas perspectivas da inclusão de todos os alunos, seja para eventos ou dinâmicas aulas, tal como se mostrou neste estudo.

\section{Referências}

ALARCÃO, I. A Formação Reflexiva de Professores: Estratégias de Supervisão. Porto: Ed. Porto, 1996.

ARMSTRONG, F. Educação inclusiva: culturas escolares, ensino e aprendizagem. In: ARMSTRONG, F.; RODRIGUES, D. (Orgs.). A Inclusão nas Escolas. Lisboa: Fundação Francisco Manuel dos Santos, p. 13-29, 2014.

ARMSTRONG, F.; MOORE, M. Investigação - Acção: Desenvolvendo práticas inclusivas e transformando culturas. In: ARMSTRONG, F.; RODRIGUES, D. (Orgs.). A Inclusão nas Escolas. Lisboa: Fundação Francisco Manuel dos Santos, p. 57-71, 2014.

BARDIN, L. Análise de conteúdo. Lisboa: Ed. Edições Rev. Atual. 70, 2011

CANÁRIO, R. Inovação: uma relação nova entre o centro e a periferia. In: NÓVOA, António (Org.). As organizações escolares em análise. Lisboa: Dom Quixote, p. 165-187, 1992.

CHICON, J. F.; SÁ, M.G.C.S. A autopercepção de alunos com deficiência intelectual em diferentes espaços-tempos da escola. Revista Brasileira Ciências do Esporte, Florianópolis, v. 35, n. 2, p. 373-388, abr./jun. 2013.

CHICON, J. F.; SILVA, J. P. A mediação pedagógica do professor de Educação Física: encontrando caminhos para a inclusão. XI Congresso Espirito-Santense de Educação Física: Educação Física nas Políticas Públicas; Espírito Santo, 2011. 
EBBING, D. S.; BRITTES, L. R. Educação Inclusiva: entre questões de direitos humanos e auto-investimento: desdobramentos a partir da lógica neoliberal. Revista Educação Especial, v. 29, n. 54, p. 175-188, jan./abr. 2016.

EL TASSA, K. O. M.; CRUZ, G. C. Formação docente e inclusão escolar em um curso de Licenciatura em Educação Física. Revista Educação Especial, v. 29, n. 54, p. 121-132, jan./abr. 2016.

FALKENBACH, A.P et al. Experiências de inclusão nas aulas de educação física: um olhar sobre a participação de alunos com deficiência. In: CHICON, J. F., RODRIGUES, G. M. (Orgs.). Práticas pedagógicas e pesquisa em Educação Física Escolar Inclusiva. Vitória: EDUFES, p. 129-148, 2011.

GITAHY, R. R. C. et al. O uso das tecnologias de informação e comunicação aplicadas como tecnologia assistiva na construção do conhecimento dos alunos com deficiência visual que frequentam as salas de recursos multifuncionais. Revista Ibero-Americana de Estudos em Educação, v.11, n. 1, 2016.

GUIZZO, B. C. F. A inclusão de alunos com deficiência no ensino regular: o que pensam os professores de educação física? Trabalho de conclusão de curso. Universidade Estadual de Santa Catarina, 2014. Disponível em: http://repositorio.unesc.net. Acesso em: 24 abr. 2016.

IMBERNÓN, F. Formação Docente e profissional: formar-se para a mudança e incerteza. Coleção Questões da nossa Época, n. 77, São Paulo: Ed. Cortez, 2000.

LIMA, L. F. L. et al. O profissional da educação física e a inclusão dos alunos com deficiência no ensino regular. Revista Poiésis Pedagógica, v. 5/6, p. 125-145, jan./dez. 2007/2008.

LIMA, S. M. T. Pesquisas e experiências com a educação física no contexto das práticas pedagógicas escolar e não escolar. In: CHICON, J. F., RODRIGUES, G. M. (Orgs.). Práticas pedagógicas e pesquisa em Educação Física Escolar Inclusiva. Vitória: EDUFES, p. 13$38,2011$.

MANTOAN, M. T. E.; O direito de ser, sendo diferente, na escola. R. CEJ, Brasília, n. 26, p. 36-44, jul./set. 2004.

NEVES, M. C. Escola inclusiva: entre o ideal (necessário) e o real (possível). Revista Encontros, n. 20, ano11, jan/jun. 2013.

NÓVOA, A. Os professores a sua formação. Lisboa: Publicações Dom Quixote, 1992.

RODRIGUES, D. Equidade e Educação Inclusiva. Porto: Coleção A Página, 2013.

RODRIGUES, D. Os desafios da equidade e da inclusão na formação de professores. In: ARMSTRONG, F.; RODRIGUES, D. (Orgs.). A Inclusão nas Escolas. Lisboa: Fundação Francisco Manuel dos Santos, p.75-102, 2014.

RODRIGUES, G. M.; FREITAS, D. P.; Saber do que sabe a pessoa com deficiência: Reflexões sobre a família e a escola na prática pedagógica. In: CHICON, J. F., RODRIGUES, G. 
M. (Orgs.). Práticas pedagógicas e pesquisa em Educação Física Escolar Inclusiva. Vitória: EDUFES, p. 109-127, 2011.

SALDANHA, S. N. et al. A Inclusão de crianças com necessidades educacionais especiais na prática pedagógica de uma escola municipal do município de Vila Nova do Sul. Revista Monografias Ambientais - REMOA v. 14, p. 143-154, 2015.

SILVA, A. N. C. O direito à acessibilidade e a inclusão escolar: um estudo de caso de uma escola pública do distrito federal. Trabalho final de conclusão de curso. Universidade de Brasília/Faculdade de Educação, 2013.

THOMAS, J. R; NELSON, J. K; Métodos de pesquisa em atividade física. Trad. Ricardo Petersen et al, 3 ed.; Porto Alegre: ArtMed, 2002.

Recebido em: $15 / 02 / 2018$

Revisado em: 25/02/2019

Aprovado em: 15/03/2019

Endereço para correspondência:

milena.educacaofisica@gmail.com

Milena Pedro Morais

Universidade São Judas Tadeu, Curso de Pós-Graduação Stricto Sensu em Educação Física.

Rua Taquari, 546

Mooca

03166000 - São Paulo, SP - Brasil 